\title{
A UTILIZAÇÃO DAS IMAGENS DE RADAR METEOROLÓGICO EM CLIMATOLOGIA
}

MARCELO FRAGOSO ${ }^{1}$

\begin{abstract}
Resumo - Apresenta-se uma breve caracterização do radar meteorológico como instrumento de teledetecção. São abordados alguns aspectos importantes que se prendem com as imagens de radar meteorológico, nomeadamente as potencialidades que estas proporcionam aos seus utilizadores, assim como as suas principais limitações. Destacando-se o interesse da sua inclusão em estudos de Climatologia, procede-se à apresentação de um exemplo da utilização das imagens de radar meteorológico, efectuada no âmbito de um estudo respeitante a dois episódios chuvosos observados em Nancy (França), em Abril de 1995.
\end{abstract}

Palavras-chave: radar meteorológico, precipitação.

\begin{abstract}
Weather Radar Image in Climatology - After a brief overview about weather radar as a remote sensing instrument, some problems concerning the use of radar images are discussed. The great interest of radar images as a tool in Climatology is pointed out. Finally, a case study about two rainfall events in Nancy (France) in April 1995 is presented.
\end{abstract}

Key-words: weather radar, rainfall.

\section{1 - O RADAR METEOROLÓGICO COMO INSTRUMENTO DE TELEDETECÇÃO}

Foi na década de 40, na sequência de progressos tecnológicos induzidos pela Segunda Grande Guerra Mundial, que o Radar (termo nascido da contracção das iniciais de "RAdio Detection And Ranging") surgiu como um instrumento de teledetecção usado em Meteorologia. No âmbito desta ciência, aquela tecnologia assumiu rapidamente uma enorme importância, começando por ser utilizada com um intuito essencialmente descritivo dos sistemas atmosféricos. Nos anos 50, os trabalhos efectuados utilizando esta técnica de teledetecção revelaram-se contributos decisivos para o desenvolvimento de um novo domínio nas ciências da atmosfera, tendo como objecto de estudo os fenómenos de meso-escala. Assim, segundo ATKINSON (1981), terá sido na primeira conferência sobre o radar meteorológico, realizada em 1953, que surgiu o termo "Meso-meteorologia", conceito que, na terminologia usada por este autor, se refere ao estudo dos sistemas atmosféricos de dimensões intermédias entre as dos fenómenos observados à escalas "local" e "sinóptica". A utilização do radar meteorológico em estudos com uma abordagem quantitativa, isto é, com vista, por exemplo, à medição ou estimação da precipitação ou velocidade de progressão dos sistemas pluviogénicos, iniciou-se a partir de 1970 (SAUVAGEOT, 1982; DELRIEU et al., 1988).

Mais recentemente, diversificaram-se as áreas de aplicação do radar meteorológico, destacando-se a sua importância na previsão, a curto e médio prazo, de episódios de precipitação intensa, potencialmente causadores de cheias rápidas e inundações. A utilização, de forma integrada, das imagens de radar e de técnicas estatís-

\footnotetext{
${ }^{1}$ Assistente do Departamento de Geografia da Faculdade de Letras de Lisboa e Investigador do Centro de Estudos Geográficos, Faculdade de Letras de Lisboa, Alameda da Universidade, 1699 Codex. Tel.: (351-1) 794 0218 Fax: (351-1) 79386 90; E-mail: nop0473@ telepac.pt.
} 
ticas de interpolação espacial dos dados fornecidos pelas redes pluviométricas convencionais, afigura-se, neste domínio, como a metodologia que tem produzido resultados mais satisfatórios (SAUVAGEOT, 1983; ROUSSEL, 1995).

Em Portugal, a previsão da precipitação, assente neste tipo de estudos, teve início em 1992, com a instalação de um radar meteorológico no Aeroporto de Lisboa. Para além do seu papel na previsão meteorológica a muito curto prazo (3 horas), os estudos que têm sido realizados com os dados do radar de Lisboa, visam também a sua utilidade como instrumento de alerta quanto ao risco de inundações em bacias-vertente da região, como a bacia de Alenquer (RODRIGUES, 1994; SARAMAGO, 1994).

\section{2 - PRINCÍPIOS BÁSICOS DO FUNCIONAMENTO DO RADAR METEO- ROLÓGICO}

O radar meteorológico é um aparelho que emite para a atmosfera impulsos de energia electromagnética muito breves (na ordem dos micro-segundos), em comprimentos de onda entre 5 e $10 \mathrm{~cm}$, possuindo forte potência (100 a 1000 kilowatts) e alta frequência. A energia é concentrada num feixe de fraca abertura e dirigida por uma antena. $\mathrm{O}$ encontro dum obstáculo provoca a difusão das ondas incidentes em todas as direcções, sendo uma parte reenviada para o radar, representando o que se designa por eco útil. Para o radar meteorológico os alvos do feixe são as precipitações, isto é, as gotículas de água em queda. As gotículas de água constituintes das nuvens, quando são atingidas pelas ondas electromagnéticas, geram uma difusão diferente, não surgindo nas imagens elaboradas a partir da recepção energética pelos radares meteorológicos.

Num dado radar meteorológico, o diâmetro da antena (d) e o comprimento de onda da energia emitida $(\lambda)$ definem a largura do feixe $(\theta)$ que é enviado, de acordo com a seguinte expressão:

$$
\theta=0,85(\lambda / \mathrm{d})
$$

O conhecimento permanente da orientação do feixe, definida pelo ângulo de azimute (ângulo que o feixe principal faz relativamente ao Norte geográfico), e pelo ângulo que o feixe forma com a horizontal, bem como a medição do intervalo de tempo entre a emissão das ondas e a recepção dos ecos, permitem a localização precisa do obstáculo (SAUVAGEOT, 1982). O radar meteorológico constitui, deste modo, um instrumento de teledetecção activo, cujos movimentos da antena permitem uma exploração tridimensional da baixa atmosfera.

Os ecos recebidos pelo radar podem fornecer "informações respeitantes às propriedades do meio observado (granulometria das gotas de chuva, a sua velocidade média e turbulência), bem como quanto à repartição espaço-temporal destes parâmetros" (SAUVAGEOT, 1982, p. 4). As precipitações são, assim, detectadas com base na energia que é retrodifundida, a qual é igual à soma das quantidades de energia reflectidas por cada uma das gotas em queda pertencentes ao volume unitário considerado.

A aptidão de um alvo para difundir a energia incidente pode ser expressa por um parâmetro designado por "reflectividade radar" $(Z)$. No caso da precipitação, Z é dado pela seguinte equação:

$$
\begin{gathered}
\mathrm{Z}=\sum_{\mathrm{i}} \mathrm{D}_{\mathrm{i}}^{6} \text { em que, } \mathrm{D} \text { descreve o diâmetro do conjunto das gotas } \\
\text { de água do volume considerado. }
\end{gathered}
$$

A potência retrodifundida (pr), que é a grandeza experimentalmente medida, está relacionada com a "reflectividade radar" (Z) pela expressão: 


$$
\mathrm{pr}=\mathrm{CL}(\mathrm{r}) \frac{\mathrm{Z}}{\mathrm{r}^{2}}
$$

em que, r é a distância do radar ao alvo, C é uma constante característica do radar, $\mathrm{L}(\mathrm{r})$ é função da atenuação do eco com a distância; $\mathrm{L}(\mathrm{r})=1$ para radares que emitem comprimentos de onda entre 5 e $10 \mathrm{~cm}$.

$\mathrm{O}$ factor de reflectividade radar $\mathrm{Z}$ constitui a informação que, por fim, é utilizada na elaboração das imagens numerizadas.

A intensidade da chuva ( $\mathrm{R}$ em $\mathrm{mm} /$ hora) pode ser definida como o volume de água que atravessa uma dada superfície, por unidade de tempo. Ela depende da velocidade de queda das gotas de chuva, do seu diâmetro e da sua repartição granulométrica no seio do volume considerado. Foram estabelecidas relações experimentais entre a intensidade da precipitação - $\mathrm{R}$ - e a reflectividade radar, as quais são do seguinte tipo:

$$
\begin{gathered}
\mathrm{Z}=\mathrm{a} \mathrm{R}^{\mathrm{b}} \text {, em que a e } \mathbf{b} \text { são parâmetros que dependem } \\
\text { da origem das precipitações. }
\end{gathered}
$$

Segundo a lei de Marshall-Palmer, a mais utilizada destas relações experimentais, o valor do coeficiente a é de 200 e o de b é de 1,6. Estes valores revelam-se mais adequados para a determinação de intensidades no caso de chuvas finas e contínuas. De acordo com a lei de Jones, estabelecida para os casos de chuvas convectivas, o coeficiente a corresponderá a 486, enquanto b será igual a 1,3 (SAUVAGEOT, 1982 e 1983). De referir que a aplicação destas relações empíricas pressupõe sempre o conhecimento, em cada caso, da repartição granulométrica das gotas de chuva, a qual depende de um conjunto de processos microfísicos e cinemáticos (evaporação, coalescência, agregação e outros), elementos que, dada a sua difícil determinação, na maioria das vezes, não são considerados (DELRIEU et al., 1988).

Para além da intensidade da precipitação, as imagens obtidas com base no radar meteorológico podem fornecer informações que permitam deduzir, por exemplo, a natureza das nuvens responsáveis pelas chuvas. Os ecos homogéneos na sua repartição e intensidade podem traduzir a presença de nuvens estratiformes, como os nimbostratus. Os ecos intensos, mais descontínuos e isolados, são geralmente reveladores de nuvens cumuliformes, do tipo cumulonimbus (COTTON e ANTHES, 1989). Assim, em certa medida, o radar e o satélite meteorológicos poderão constituir instrumentos de teledetecção complementares: se as imagens captadas por satélite permitem mais facilmente distinguir, a pequena escala, a fisionomia e natureza das nuvens, as imagens de radar podem proporcionar, a individualização das áreas de chuva, e, dentro destas, os núcleos de maior intensidade de precipitação.

\section{3 -OS LIMITES E OS PROBLEMAS DA UTILIZAÇÃO DO RADAR METEOROLÓGICO}

O radar meteorológico apresenta, como instrumento de teledetecção, várias vantagens que se poderão assim enumerar (segundo SAUVAGEOT, 1982):

- permite uma teledetecção activa dos fenómenos, neste caso, a precipitação. Não requer que os instrumentos de medição sejam deslocados, sendo possível, contudo, a escolha precisa do volume de ar sondado;

- proporciona uma exploração tridimensional de grandes volumes de ar e ao longo do tempo; 
- a resolução e a continuidade das observações, tanto no tempo como no espaço, são satisfatórias para muitas aplicações;

- a observação não perturba o meio no qual é feita;

- os dados ficam imediatamente disponíveis.

Não obstante estas vantagens, o radar meteorológico possui algumas limitações que importa ter sempre em consideração, não devendo, também, ignorar-se o elevado custo que a sua instalação e equipamento acarretam.

Uma limitação extremamente importante prende-se com o facto de o radar meteorológico possuir um determinado alcance, o qual, podendo variar, não vai além dos $200 \mathrm{~km}$. A distâncias superiores, as precipitações tornam-se indetectáveis ou a sua medição processa-se com uma larga margem de erro, devendo referir-se ainda que, segundo o North Weather Radar Project (1985, citado por DELRIEU et. al., 1988), o limite da utilização quantitativa das imagens radar foi estimado num raio de $75 \mathrm{~km}$.

Um outro aspecto desta técnica de teledetecção que pode colocar algumas restrições à sua utilização reside na resolução das imagens. Embora para muitas aplicações, a resolução espacial e a cadência de recepção das imagens de radar sejam francamente satisfatórias, normalmente, um eco pontual numa imagem de radar corresponde a uma célula de várias centenas de metros de lado e de altura, por vezes, alguns milhares. Nalgumas aplicações, esta resolução e a frequência de recepção das imagens poderão ser insuficientes, nomeadamente no domínio da Hidrologia Urbana, e quando a sua utilização tem em vista a gestão, em tempo real, das águas pluviais nas redes de saneamento (ANDRIEU e JACQUET, 1987).

Entre as várias limitações inerentes às imagens de radar meteorológico, a margem de erro que estas possam conter é, possivelmente, o que mais preocupa os seus utilizadores. De facto, os erros que afectam a medição das precipitações pelo radar meteorológico podem ser muito importantes, chegando a desaconselhar-se, nalguns casos, uma utilização quantitativa das intensidades estimadas. Apesar dos progressos recentes realizados no domínio da correcção destes erros, torna-se indispensável, ao utilizador das imagens, dispor de um registo sincrónico das precipitações observadas ao nível do solo, a partir de uma rede de udógrafos densa (que fornece, ainda que pontualmente, uma maior precisão na medição directa da chuva, enquanto o radar permite a detecção da repartição espacial das precipitações e uma medição indirecta da sua intensidade). As principais fontes de erros na estimação da intensidade da chuva pelo radar meteorológico prendem-se com os seguintes aspectos (segundo SAUVAGEOT, 1982):

- a intercepção do feixe do radar por obstáculos (relevo, construções) pode determinar a medição de reflectividades sem qualquer relação com as precipitações. São os chamados ecos de solo que, por serem quase constantes e visíveis nas imagens com tempo seco, são de fácil identificação. Por outro lado, as zonas de chuva que são ocultadas por esses obstáculos não recebem senão uma parte do feixe do radar, pelo que a medição da reflectividade é subestimada (efeito de ocultação);

- com o afastamento ao radar, o feixe vai-se atenuando, decrescendo o grau de rigor na estimação das intensidades. Os erros relacionados com o fenómeno de atenuação tendem a ser importantes, sobretudo nas zonas de forte intensidade de precipitação. A atenuação depende, essencialmente, do comprimento de onda da energia emitida, sendo praticamente negligenciável para radares de comprimento de onda de 5 a $10 \mathrm{~cm}$, mas, pelo contrário, muito importante para um radar de $3 \mathrm{~cm}$ de comprimento de onda; 
- determinados erros poderão ocorrer quando o feixe do radar atinge um nível em que temperatura é de $0^{\circ} \mathrm{C}$, à qual estão associadas as mudanças de estado físico gelo/água. Quando se atinge essa temperatura, as partículas de gelo modificam-se e, numa primeira fase, ficam cobertas por uma fina película de água, o que faz aumentar o seu diâmetro. Elas retomam as suas dimensões normais apenas após a passagem completa ao estado líquido. Esta mudança de estado gelo-água traduz-se nas imagens de radar por um pico de reflectividade (banda brilhante), desde que as ondas incidentes atinjam a isotérmica de $0^{\circ} \mathrm{C}$;

- as relações $\mathrm{Z} / \mathrm{R}$ (entre a reflectividade radar e intensidade da precipitação) são válidas para hipóteses muito restritivas quanto à homogeneidade do alvo do radar. A distribuição granulométrica das precipitações pode variar no espaço e no tempo no decurso do mesmo episódio chuvoso.

Por todas estas razões, a interpretação quantitativa das imagens de radar constitui uma tarefa muito delicada, exigindo a realização de procedimentos de correcção que permitam não só atenuar os erros atrás enunciados, mas também ultrapassar o problema dos fenómenos de advecção (dependente do perfil vertical do vento, que provoca um deslocamento horizontal das gotículas em queda, condicionando também a sua evaporação parcial...) que afectam a medição da intensidade da chuva. Esta complexidade leva a que muitos utilizadores das imagens de radar adoptem uma abordagem com um carácter mais qualitativo, na qual as intensidades reveladas no ecrã são interpretadas, essencialmente, em termos de ordens de grandeza.

\section{4-A COMPLEMENTARIDADE DOS DADOS REGISTADOS PELOS UDÓGRAFOS E DAS IMAGENS DE RADAR}

A utilização das imagens de radar meteorológico com vista ao estudo da repartição espacial da precipitação apresenta algumas vantagens relativamente aos dados fornecidos pelas redes de estações pluviométricas. A mais importante assenta na continuidade espacial das observações, facto que permite, por exemplo, a individualização de células convectivas responsáveis por precipitações intensas que, muitas vezes, não se detectam ou são incorrectamente avaliadas através dos registos pontuais dos udógrafos (SAUVAGEOT, 1983). Saliente-se ainda que, ao proporcionar a configuração das áreas de chuva, o radar meteorológico pode mesmo constituir um instrumento de validação dos dados, contribuindo, em certos casos, para a detecção dos aparelhos que, numa rede de udógrafos, acusam erros ou deficiências de funcionamento (RouSSEL, 1995).

Outra vantagem da utilização das imagens de radar meteorológico, quando comparada com a informação dos udógrafos, consiste na possibilidade de monitorizar a precipitação, em tempo real, numa área relativamente extensa e não apenas num ou vários pontos de uma rede, por mais densa que seja. A aquisição, armazenamento e tratamento informático das imagens processa-se, também, de forma mais fácil que no caso dos bancos de dados pluviométricos (SAUVAGEOT, 1983).

A grande desvantagem das imagens de radar, referida pela generalidade dos autores, prende-se com a precisão das medições, fortemente condicionada pelos problemas anteriormente enunciados. A conjugação das imagens de radar com os dados registados numa rede densa de udógrafos permite a minimização dos erros na estimação da precipitação e da sua repartição no espaço. Desse modo, "associa-se a qualidade pontual das medições dos udógrafos com a continuidade espacial das imagens de radar" (ANDRIEU e JACQUET, 1987, p. 449), obtendo-se um conhecimento mais correcto da variabilidade da chuva no tempo e no espaço. 


\section{5 - O INTERESSE DA UTILIZAÇÃO DAS IMAGENS DE RADAR EM CLIMATOLOGIA}

O radar meteorológico tem sido utilizado como instrumento de teledetecção essencialmente por meteorologistas, físicos da atmosfera e hidrólogos. As possibilidades que esta técnica veio oferecer proporcionaram a realização de estudos muito diversos, úteis a diferentes domínios das Ciências da Atmosfera (segundo SAUVAGEOT, 1982):

- desenvolveram-se os estudos dos fenómenos ligados às precipitações, tornando possível uma melhor identificação das estruturas que as originam, bem como a avaliação da sua perigosidade; por vezes estes estudos centram-se numa perspectiva de previsão a médio ou a curto prazo;

- tornou-se possível proceder à medição sistemática de grandezas físicas, indispensáveis à preparação de previsões;

- o radar veio permitir a aquisição de conhecimentos importantes para a concepção de esquemas ou modelos funcionais das estruturas e fenómenos atmosféricos.

Se no âmbito da Meteorologia estas novas possibilidades vieram significar importantes avanços, também outras ciências procuraram, mais recentemente, tirar partido deste meio de teledetecção. É o caso da Hidrologia, nomeadamente a Hidrologia Urbana, na qual o radar meteorológico constitui um equipamento muito útil na gestão das redes de saneamento, podendo ser um instrumento de alerta face às situações de chuvas muito intensas. Segundo HAMmOUda (1995), uma das áreas em que, actualmente, mais se centram os trabalhos de Hidrologia Urbana é, justamente, o problema da estimação das intensidades de precipitação, em tempo real ou no prazo de alguns minutos a algumas horas, combinando medições pluviométricas e dados de radar.

A Climatologia é outro dos domínios em que as imagens de radar constituem um instrumento de trabalho com uma crescente utilização, sendo de sublinhar a sua aplicação em estudos que abordam as situações atmosféricas responsáveis por precipitações intensas. Os episódios de chuva muito intensa relacionam-se, muitas vezes, com fenómenos de meso-escala (como trovoadas, frentes convectivas, sistemas convectivos de meso-escala), cuja configuração e dinamismo só nas imagens de radar são revelados. Na bibliografia recente são já muitos os estudos de climatologia nos quais as imagens de radar são utilizadas com esse intuito, podendo citar-se, apenas a respeito da Bacia Mediterrânea, os trabalhos de RUDOLPH e SiouTAS (1993, relativo à Macedónia), BARRET et al. (1994, Sudeste de França e Córsega), DuFIEF (1994, Sudeste de França) e CHALON et al. (1995, Sudoeste de França). DuFIEF, único geógrafo entre os citados, estudou alguns episódios de chuvas excepcionalmente intensas na região de Marselha, conjugando a análise de cartas sinópticas, de imagens de satélite (Meteosat) e de radar, metodologia que se nos afigura de muito interesse neste tipo de estudos climáticos. Na Climatologia praticada por geógrafos, na qual muitas vezes sobressai a importância dada à interacção do substrato geográfico com os sistemas atmosféricos, as imagens de radar meteorológico apresentam-se como um instrumento de trabalho de grande utilidade. A observação de uma sequência de imagens transmite, de facto, uma percepção aproximada da complexa dinâmica dos sistemas pluviogénicos, fornecendo elementos relativos ao modo como aqueles evoluem nas escalas regional ou local. A inclusão da análise das imagens de radar associadas a determinadas situações atmosféricas, previamente consideradas, pode, deste modo, constituir um contributo muito importante nos estudos onde se adopte uma perspectiva geográfica na abordagem das precipitações. 
6-UM EXEMPLO DA UTILIZAÇÃO DAS IMAGENS DE RADAR: ESTUDO DE DOIS EPISÓDIOS CHUVOSOS NA AGLOMERAÇÃO URBANA DE NANCY (FRANÇA)

Apresenta-se, em seguida, uma breve síntese do trabalho referido no início desta nota, no qual foram estudados alguns aspectos de dois episódios chuvosos na aglomeração urbana de Nancy. Esta cidade, para além de dispor de uma densa rede de udógrafos, é servida por um radar meteorológico, situado $50 \mathrm{~km}$ para Este, oferecendo condições adequadas para o estudo das suas características pluviométricas.

O estudo dos dois episódios envolveu a abordagem dos seguintes aspectos:

- utilização dos registos da rede de udógrafos da aglomeração (23 no total), informação com base na qual se procedeu à definição temporal dos dois episódios chuvosos. Os dados diários e os hietogramas (elaborados segundo períodos de tempo de cinco minutos), permitiram caracterizar os episódios chuvosos quanto ao ritmo das precipitações, bem como a evolução da sua repartição no espaço;

- análise das condições atmosféricas associadas aos dois episódios chuvosos, utilizando as cartas sinópticas de superfície e dos $500 \mathrm{hPa}$;

- análise das imagens de radar, com uma cadência de 15 minutos.

O primeiro episódio chuvoso, que teve uma duração de cerca de 18 horas (das 5 h00 às 23h00 de 17/3/1995), foi responsável por chuvas não muito abundantes em Nancy, atingindo-se um valor máximo acumulado de $15 \mathrm{~mm}$. Caracterizou-se, excepto na sua parte final, pela ocorrência de chuva fraca, com um carácter persistente e generalizado, na dependência da passagem da frente quente de uma perturbação e do seu sector quente, que atravessaram a aglomeração de NW para SE.

A análise das imagens de radar correspondentes à parte final deste episódio revelaram aspectos muito interessantes das estruturas responsáveis pelas chuvas, e que não podiam ser interpretados a partir das cartas sinópticos. Com efeito, constatou-se nas imagens de radar desse período que a aglomeração de Nancy foi abordada por dois sistemas pluviogénicos com características de circulação diferentes. A coexistência destes dois sistemas pluviogénicos está bem patente na figura 1, na qual se pode ver ${ }^{2}$ que enquanto se verificava a progressão para SE de uma extensa banda de precipitação, alongada no sentido SW-NE (visível a $\mathrm{N}$ da aglomeração), ao mesmo tempo, Nancy era atingida por uma sucessão de células estreitas e curtas, com disposição e trajectória sensivelmente perpendiculares. As características deste segundo sistema pluviogénico, com áreas de ascendência, chuvosas, separadas por zonas sem chuva (subsidência), sugerem uma organização do escoamento do ar de tipo ondulatório. Muito possivelmente, estas estruturas corresponderão a fenómenos atmosféricos pré-frontais, precursores, neste caso, da chegada duma frente fria que atingiu a aglomeração no decurso deste episódio chuvoso.

2 Pelo facto de não ter sido possível reproduzir as imagens a cor, foi necessário modificá-las, de forma a apresentar as variações na intensidade da precipitação segundo uma escala de cinzentos. De salientar que esta adaptação obrigou a uma simplificação e a uma generalização que impedem que as figuras tenham uma leitura quantitativa. 
$18 \mathrm{~h} 15$

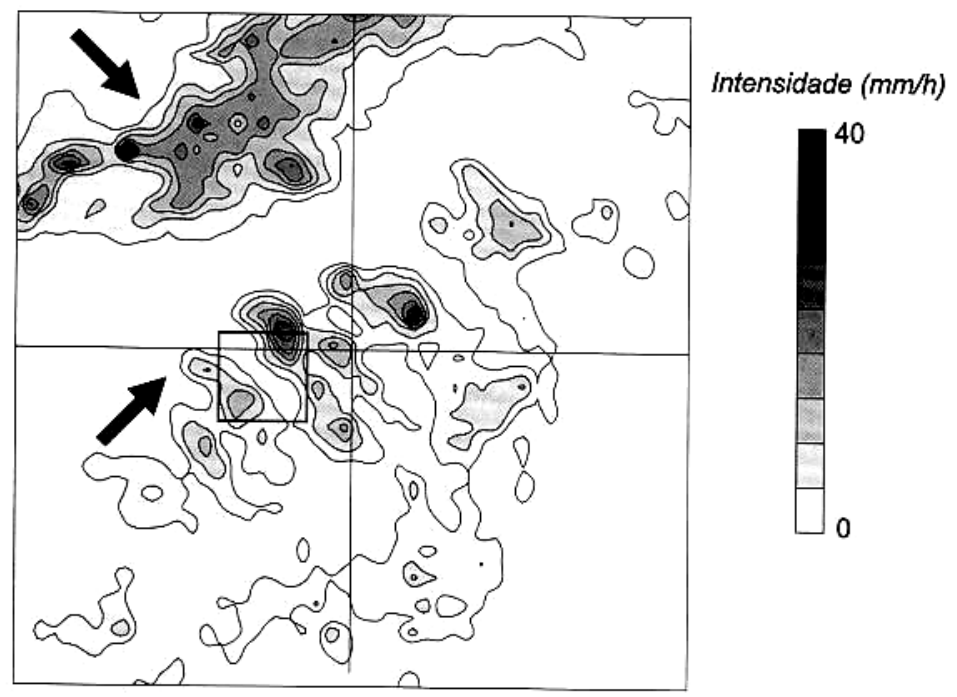

\section{$18 \mathrm{~h} 25$}

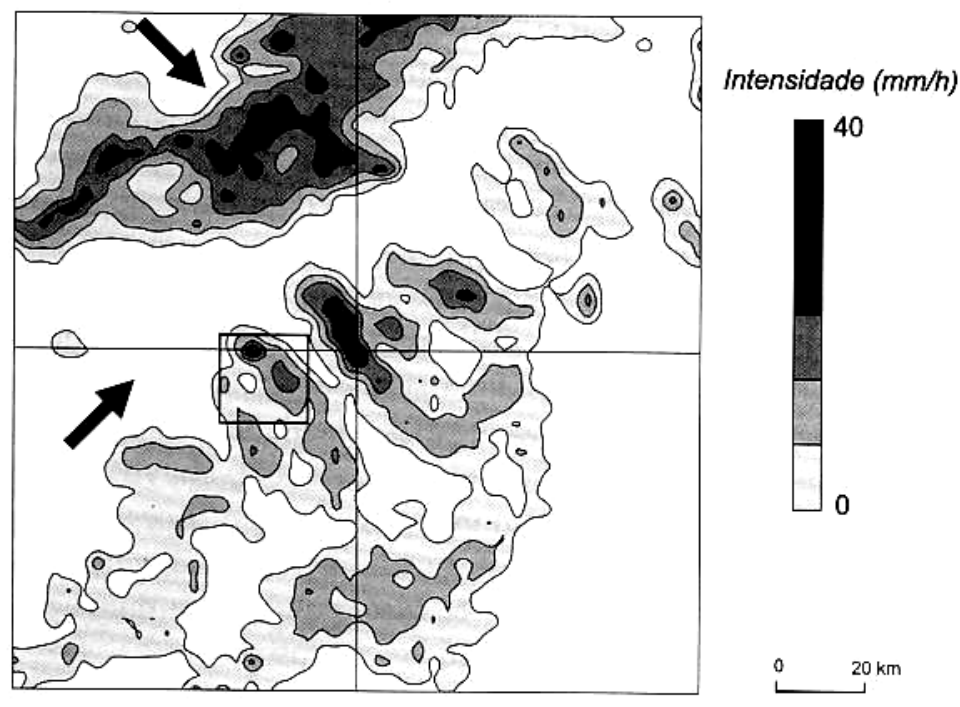

Área de Nancy

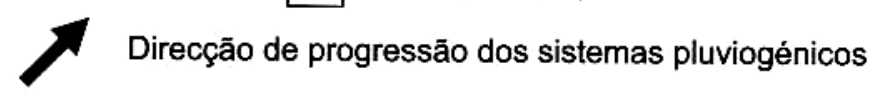

Figura 1 - Evolução espaço-temporal da precipitação ocorrida na região de Nancy entre as $18 \mathrm{~h} 15$ e as $18 \mathrm{~h} 25$ de 17 de Março de 1995.

Figure 1 - Rainfall in Nancy on March $17^{\text {th }} 1995$, between $16 \mathrm{~h} 15$ and $18 \mathrm{~h} 25$.

As precipitações do segundo episódio chuvoso, que durou cerca de 24 horas (entre $15 \mathrm{~h} 00$ de 18/3 e $15 \mathrm{~h} 00$ de 19/3/1995), foram bem mais abundantes que as do primeiro, tendo-se registado, consoante os postos da aglomeração, totais acumulados entre 40 e $50 \mathrm{~mm}$. Apesar desta abundância, as chuvas não ocorreram, contudo, com muito forte intensidade. Segundo a análise dos documentos sinópticos, este episódio terá sido condicionado pela instabilidade verificada no ar frio posterior de uma perturbação, facto que foi possível comprovar através da observação das imagens de radar. Na verdade, a análise da sequência de imagens de radar correspondentes ao segundo episódio permitiu confirmar que este se iniciou com chuva fraca, embora 
generalizada na área alcançada pelo radar, assistindo-se depois a um claro recrudescimento da precipitação. Na figura 2 apresenta-se a evolução do sistema pluviogénico responsável por este incremento da chuva, podendo constatar-se que se tratou de uma linha de instabilidade, associada a uma perturbação que já progredira para sul de Nancy, orientada segundo uma direcção WSW-ENE. O dinamismo desta linha de instabilidade está bem patente na progressão muito rápida testemunhada nestas quatro imagens, tendo-se estimado que o sistema pluviogénico abordou Nancy depois de se ter deslocado cerca de $60 \mathrm{~km}$ em 3 horas, aproximadamente.

\section{CONCLUSÃO}

Os exemplos apresentados procuram ilustrar como as imagens de radar podem fornecer elementos difíceis de obter pelos meios clássicos mas que são muito úteis para a interpretação de aspectos como a configuração dos campos pluviométricos e sua evolução no tempo e no espaço, direcção e velocidade de progressão dos sistemas pluviogénicos ou, ainda, a identificação das zonas de maior instabilidade convectiva. Estas potencialidades de utilização fazem das imagens de radar um instrumento de análise com interesse em Climatologia, nomeadamente no que diz respeito aos estudos climáticos que incidem nos fenómenos da precipitação às escalas local e regional.

\section{AGRADECIMENTOS}

Este texto foi extraído de um trabalho elaborado no decurso de um estágio integrado no programa Erasmus, efectuado em França, de Fevereiro a Abril de 1995, na Université des Sciences et Technologies de Lille, e em Nancy, no Centre International de l'Eau e no District de l'Agglomération Nancéienne (FRAGOSO, 1995). Estou reconhecido à Professora Isabelle Roussel pelo apoio prestado na organização deste estágio.

Às Professoras Doutoras Denise de Brum Ferreira, Maria Eugénia Moreira e Suzanne Daveau agradeço a leitura crítica deste texto. 

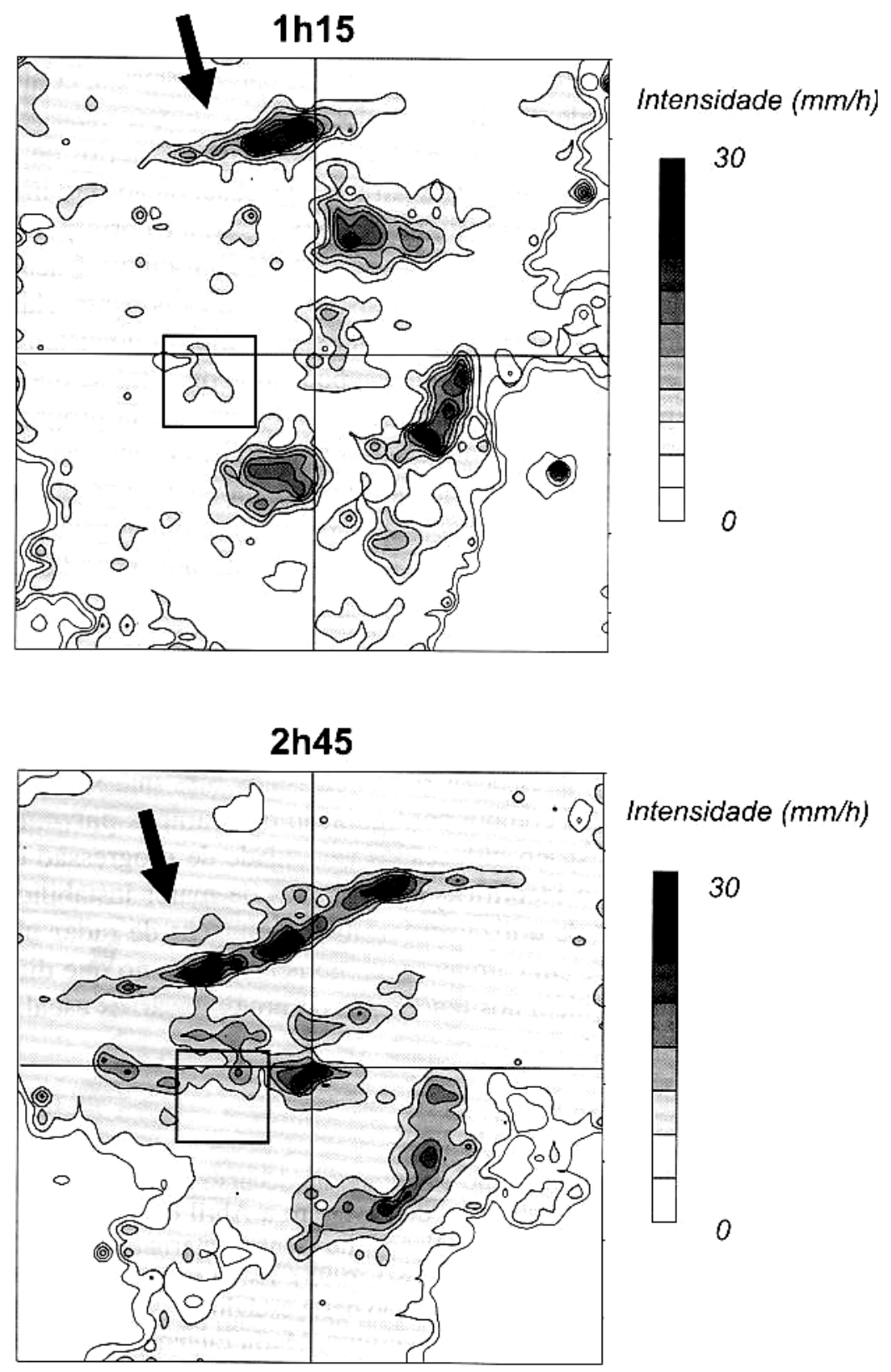

Figura 2 - Evolução espaço-temporal da precipitação ocorrida na região de Nancy entre as 1 h15 e as 4 h30 de 19 de Março de 1995. 


\section{3h45}

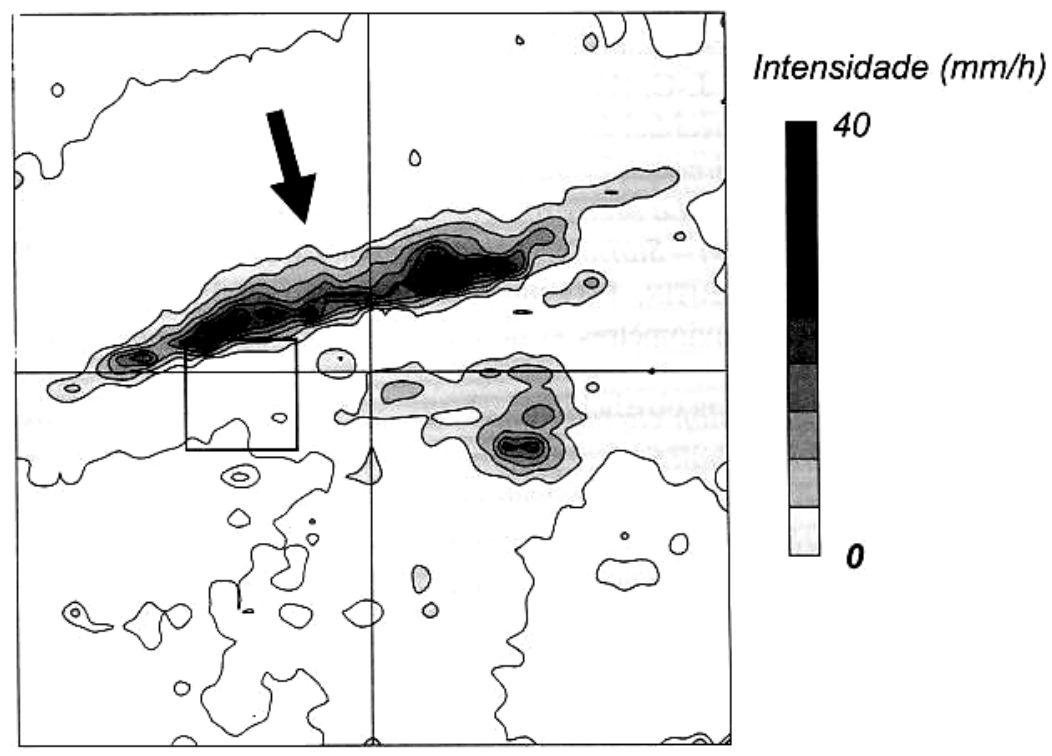

4h30

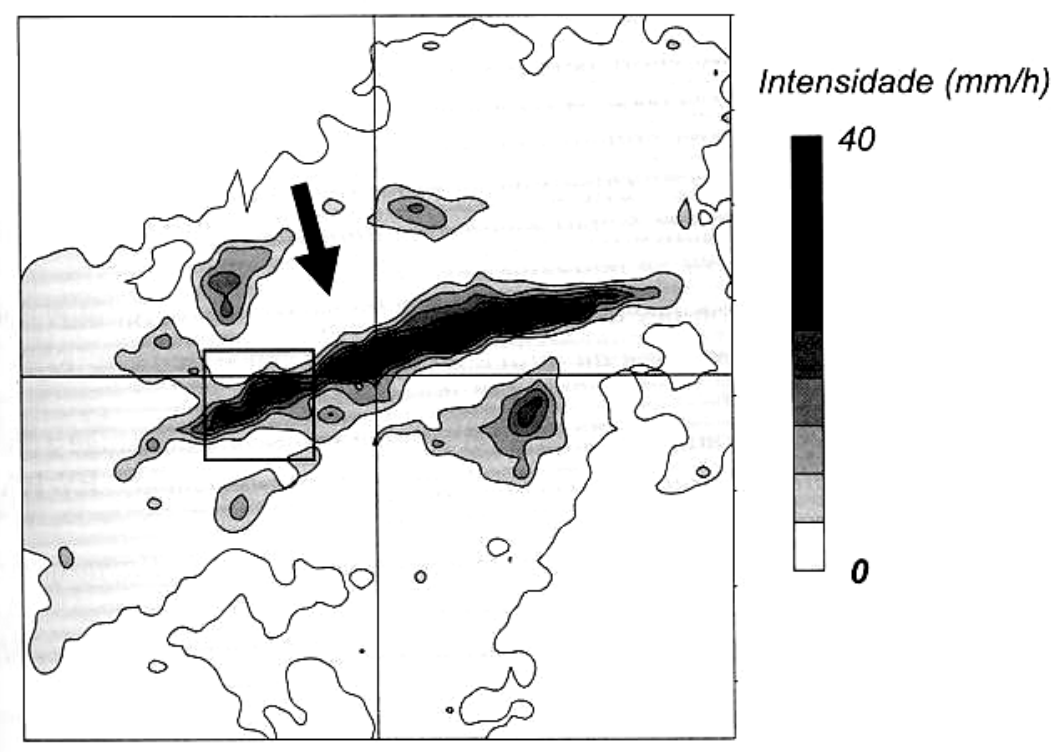

Figure 2 - Rainfall in Nancy on March $19^{\text {th }} 1995$, between 1 h15 and 4h30.

\section{BIBLIOGRAFIA}

ANDRIEU, H.; JACQUET, G. (1987) - Le radar météorologique de Trappes et l'estimation des intensités pluvieuses en Seine Saint-Denis. La Houille Blanche, 6: 447-457.

AtKInson, B. (1981) - Meso-scale atmospheric circulations. Academic Press, London.

BARRET, I.; JACQ, V.; RIVRAIN, J.-C. (1994) - Une situation à l'origine de pluies diluviennes en région méditerranéenne. La Météorologie, 8(7): 38-60.

CHAlON, J.-P. et al. (1995) - Landes-Fronts-84: Bilan d'une expérience d'étude des systèmes frontaux convectifs. La Météorologie, 8(9): 10-28.

Cotton, W.; Anthes, R. (1989) - Storm and cloud dynamics. Academic Press, London.

Delrieu, G.; Bellon, A.; CREutin, J. (1988) - Estimation des lames d'eau spatiales à l'aide de données de pluviomètres et de radar météorologique. Journal of Hydrology, 98: 315-344. 
DUFIEF, N. (1994) - Interprétation climatologique de pluies intenses dans le sud-ouest de la France. Memoire de maîtrise en Climatologie, Université de Nantes.

FRAGOSO, M. (1995) - Analyse spatio-temporelle de deux épisodes pluvieux dans l'agglomération urbaine de Nancy - Contribution des images du radar météorologique. Rapport de stage ERASMUS, realisé à l'Université des Sciences et Technologies de Lille/D.A.N.Nancy (inédito).

HAMmoudA, A. (1995) - Connaissance et modélisation des précipitations pour l'hydrologie urbaine à travers l'exemple de l'agglomération nancéienne. Thèse de Doctorat, Université des Sciences et Technologies de Lille.

JACQUET, G.;ChERON, J.; BACHOC, A.; HeRREMANS, L. (1983) - Intérêt technique et économique des radars d'investigation des précipitations en matière d'assainissement urbain. La Houille Blanche, 5/6: 341-348.

RODRIGUES, A. (1994) - A very-short period forecasting for the Lisbon weather radar. Advances in Water Resources Technology and Management, EWRA, A.A. BALKEMA, Roterdam: 393-397.

RudolPH, R.; Sioutas, M. (1993) - Climatologie radar du déplacement des cellules orageuses en Macédoine. Publications de l'Association Internationale de Climatologie, 6: 405-412.

RouSSEL, I. (1995) - Acquisition des données pluviométriques: radars ou pluviographes? Actes du colloque "De la pluie au milieu naturel", Agence de l'Eau Rhin-Meuse-NANCIE, Nancy: 21$-27$.

SARAMAGO, M. (1994) - Generating a calibration surface for radar-raingauge adjustment. Advances in Water Resources Technology and Management, EWRA, A.A. BALKEMA, Roterdam: 55-58.

SAUVAGEOT, H. (1982) - Radarmétéorologie, télédétection active de l'atmosphère. Éditions Eyrolles et CNET.ENST, Paris.

SAuvAGEOT, H. (1983) - Mesures hydrologiques par radar. La Houille Blanche, 5/6: 329-340. 